\title{
GOVERNANÇA CORPORATIVA E ESTRUTURA DE CAPITAL NAS MAIORES EMPRESAS DE CAPITAL ABERTO À LUZ DA TEORIA PECKING ORDER
}

\author{
Maysa Santos Rodrigues \\ Faculdade Integrada da Grande Fortaleza (FGF) \\ Brasil \\ José Glauber Cavalcante dos Santos \\ Universidade Federal do Ceará (UFC) \\ Brasil \\ Greyciane Passos dos Santos \\ Faculdade Integrada da Grande Fortaleza (FGF) \\ Brasil
}

Data de submissão: 11/07/2017

Data de aceite: $21 / 08 / 2018$

\begin{abstract}
RESUMO
O estudo objetiva investigar a relação entre as práticas de governança e a estrutura de capital à luz da teoria pecking order. Foram consideradas como variáveis os segmentos de listagem, além de um índice, adaptado de estudos anteriores, composto de cinco dimensões que mensuram a governança nas empresas. Como medidas de estrutura de capital, foram considerados aspectos do endividamento e da dependência financeira. Foram realizadas as análises descritivas e de correlação em uma amostra de 77 empresas, estando estas entre as maiores empresas de capital aberto para a Revista Exame Melhores e Maiores de 2016. Os resultados revelam significativa relação, com sentido negativo, entre os níveis de governança e a estrutura de capital. Mostrouse ainda que o Índice de Qualidade de Governança Corporativa não apresentou relação com as variáveis de endividamento e dependência financeira.
\end{abstract}

Palavras-chave: Conflito de Agência. Pecking Order. Estrutura de Capital.

\section{CORPORATE GOVERNANCE AND CAPITAL STRUCTURE IN THE LARGEST PUBLIC COMPANIES THROUGH PECKING ORDER THEORY}

\section{RESUMO}

This study aims to investigate the relationship between governance practices and capital structure through pecking order theory. As corporate governance variables, we considered the corporate segments and an index, based previous studies, composed by five dimensions. As capital structure measures, we used aspects of debt and financial dependence. It was realized descriptive and correlation analysis in 77 of the largest public companies of Exame Melhores e Maiores Magazine of 2016. The results show a significant and negative relationship between governance levels and capital structure. It was also presented that the Corporate Governance Quality Index was not related to the debt and financial dependence variables.

Keywords: Agency Conflict. Pecking Order. Capital Structure. 


\section{INTRODUÇÃO}

A discussão sobre o tema governança corporativa ganha destaque na medida em que o mercado de capitais se torna mais aprimorado e as firmas buscam um modelo de gestão que visa obter uma estrutura de capital ideal para o seu negócio. Neste contexto, os executivos são contratados pelas empresas com a intenção de tomar as melhores decisões a fim de maximizar a riqueza dos acionistas. Porém, por vezes, eles acabam tomando decisões que maximizam sua utilidade pessoal, o que configura o conflito de agência (SILVEIRA, 2002).

Silveira (2002) sugere que as empresas que apresentam uma estrutura de governança corporativa mais adequada podem obter melhores resultados e avaliação no preço de suas ações. Silva (2005), por sua vez, define a governança como um conjunto de princípios e práticas que procuram harmonizar a relação de conflito de interesse entre os stakeholders, com o objetivo de reduzir o custo de capital, agregar o valor e gerar assim retorno para seus acionistas.

Desta forma a utilização do mecanismo da governança poderia interferir na estrutura de capital, na composição do endividamento e na dependência financeira das empresas, porque a melhoria da estrutura de governança corporativa poderia favorecer na captação de recursos. Quando há referência ao endividamento, é importante verificar a qualidade da dívida da empresa, seja em relação à alocação do capital de terceiros e do capital próprio; ou ainda em relação ao modo de financiamento dos ativos.

Como esclarece a teoria Pecking Order, que ajuda a explicar a estrutura de capital das firmas, "as empresas optam por recursos de forma hierárquica escolhendo inicialmente as fontes de recursos internas, seguindo-se as fontes de recursos externas” (DAVID et al., 2009, p. 134), e isso é decorrente do custo do capital, já que o capital de terceiros teria maior custo. Com a governança corporativa, instrumento de mitigação dos conflitos de interesse, haveria chances de acessar capital externo, o que pode explicar a composição do endividamento das empresas. Costa Filho et al. (2016, p. 4) ressaltam que, "ao se financiar com capital próprio, a empresa reserva todos os seus fluxos de caixa para os acionistas".

Dentre as consequências da governança corporativa, haveria a facilitação do acesso ao capital a custos mais baixos, o que a partir da Pecking Order sugere o relacionamento entre as práticas de governança corporativa e a estrutura de capital. Com base no exposto, essa pesquisa responde a seguinte questão: Como se relacionam a governança corporativa e a estrutura de capital nas maiores empresas de capital aberto do Brasil? Como principal objetivo, temse o de investigar a relação entre o grau de adoção de práticas de governança corporativa e a composição do endividamento no grupo das firmas destacadas. Ainda são estabelecidos neste 
estudo os seguintes objetivos específicos: (i) caracterizar a adoção da governança corporativa nas empresas; (ii) detalhar a composição do endividamento e a dependência financeira; e (iii) mensurar a relação entre governança corporativa, endividamento e dependência financeira.

O presente trabalho justifica-se diante do intuito de corroborar com as evidências que auxiliem na ampliação do debate sobre a relação da governança corporativa, como instrumento moderador da captação de recursos nas empresas brasileiras. Isso porque, segundo o exposto por Barros, Silva e Voese $(2015$, p. 8), "a presença de atributos de governança pode gerar uma compensação em relação ao ônus sobre o passivo contraído para financiamentos de projetos empresariais de curto e longo prazo". Outra contribuição refere-se à gestão do endividamento nas firmas, visto que a identificação de variáveis interferentes na dívida contribui para avaliação junto ao financiamento dos investimentos das empresas (PRAZERES et al., 2015).

\section{REFERENCIAL TEÓRICO}

\subsection{Características da Governança Corporativa}

Segundo Silveira et al. (2002), a governança corporativa ganha destaque à medida que o mercado de capitais se torna mais disseminado. A Governança corporativa é o sistema pelo qual as empresas e demais organizações são dirigidas, monitoradas e incentivadas, envolvendo os relacionamentos entre sócios, conselho de administração, diretoria, órgãos de fiscalização e controle e demais partes interessadas (IBGC, 2015).

No Brasil, as boas práticas começaram a se expandir a partir da abertura do mercado nacional e das privatizações. Em 1995 ganhou respaldo com a criação do Instituto Brasileiro de Governança Corporativa (IBGC), que lançou em 1999 o seu primeiro Código das Melhores Práticas de Governança Corporativa. Este documento abordava temas como as diretrizes para o funcionamento do conselho de administração e a importância dos comitês instituídos. Assim as práticas de governança passaram a ser questionadas, sofrendo uma evolução para o cenário corporativo. Segundo o código, a boa governança proporciona aos proprietários segurança sobre a gestão estratégica da empresa e a monitoração da direção executiva (IBGC, 2015).

O IBGC estabelece como princípios da governança corporativa a transparência, que consiste no desejo de disponibilizar para as partes interessadas as informações que sejam de seu interesse e não apenas aquelas impostas por disposições de leis ou regulamentos; a equidade, que se caracteriza pelo tratamento justo e isonômico de todos os sócios e stakeholders, levando em consideração seus direitos, deveres, necessidades, interesses e expectativas; a prestação de contas (accountability), onde os agentes de governança assumem integralmente consequências 
de seus atos e omissões, devendo prestar contas de sua atuação; e por último tem como princípio a responsabilidade corporativa, onde os agentes de governança devem zelar pela viabilidade econômico-financeira das organizações, reduzir as externalidades negativas de seus negócios e suas operações e aumentar as positivas (IBGC, 2015).

Silveira (2002) afirma que o sistema de governança corporativa adotado pelas empresas no mundo apresenta diferenças significativas, tendo como variáveis determinantes para tais discrepâncias (i) o ambiente institucional, (ii) o sistema financeiro e (iii) o grau de proteção dos investidores. A comparação entre os sistemas de governança corporativa auxilia na avaliação para reformular as propostas e as política para sua melhoria, segundo o autor.

Nos Estados Unidos foi criada, em 2002, a Lei Sarbanes-Oxley, que é tida como a mais importante legislação do mercado de capitais desde a quebra da bolsa de Nova York, em 1929. Tem em sua base princípios de governança, e foi criada como resposta a sucessivos escândalos contábeis que atingiram grandes corporações naquele país, objetivando recuperar a confiança abalada dos investidores no mercado de capitais (SILVA; ROBLES JÚNIOR, 2008).

Consoante Silva e Robles Júnior (2008), a Lei Sarbanes-Oxley é de suma relevância, tendo em vista a existência de empresas brasileiras que possuíam American Depositary Receipts (ADRs) negociados nas bolsas de valores estadunidenses e para isso elas deveriam seguir a Lei Sarbanes-Oxley. Seu conjunto de regras exige, por exemplo, criação de um comitê de auditoria composto por membros independentes. Conforme aponta Santos (2009), o comitê de auditoria é elemento basilar na lei americana, que influencia diretamente a governança corporativa.

O comitê de auditoria é, portanto, órgão fundamental de assessoramento ao conselho de administração, para auxiliá-lo no controle sobre a qualidade das demonstrações financeiras e controles internos, visando a confiabilidade e integridade das informações a fim de proteger a organização e todos as partes interessadas. Sua constituição é considerada como boa prática de governança corporativa, sendo que sua existência não exime o conselho de administração da responsabilidade plena sobre os assuntos tratados pelo comitê, um órgão de apoio (IBGC 2015).

Silveira (2002) menciona outra boa prática de governança corporativa, a remuneração variável. O autor afirma que a remuneração variável dos conselheiros não é adotada pela grande maioria das empresas brasileiras, o que sinaliza a hipótese de que este mecanismo assume papel mais simbólico e assessorial. Deve-se ressaltar que este fato se contrapõe àqueles fatores que são considerados importantes pelos principais códigos de governança corporativa. Lazzarotto (2015, p. 99) enfatiza em seu estudo que a remuneração dos conselheiros "deve fazer jus a sua responsabilidade, experiência e qualificação”. O conselho fiscal é outro exemplo de estrutura de governança corporativa. Enquanto o comitê de auditoria é um órgão que assessora o conselho 
de administração, o conselho fiscal tem a responsabilidade de fiscalizar os atos da administração. Assim, a existência do comitê de auditoria não exclui a possibilidade da instalação do conselho fiscal, já que estes órgãos apresentam funções que são distintas e igualmente relevantes para a governança corporativa (IBGC, 2015).

Para o código das melhores práticas de governança corporativa do IBGC, o conselho de administração é uma importante dimensão componente do sistema de governança, podendo ele decidir os rumos estratégicos do negócio. Seu papel é resguardar os princípios, valores, objeto social e o sistema de governança da organização. Esse órgão deverá atuar conforme o melhor interesse da organização, monitorar a diretoria, e atuar como elo entre esta e os sócios. Além das práticas sugeridas pelo IBGC, a criação dos níveis diferenciados de governança corporativa por meio da BM\&FBovespa reforça a demanda do mercado por esses mecanismos de gestão.

Segundo Santos et. al. (2015), a criação do índice de governança pela BM\&FBovespa contribuiu com a consolidação e a aceitação das práticas de governança no mercado brasileiro. Ainda de acordo com os autores, a adesão das firmas aos níveis estabelecidos é função do grau de compromisso assumido e formalizada pela companhia, seus administradores, conselheiros fiscais e controladores junto à BM\&FBovespa. Dessa forma, as empresas se comprometem em adotar voluntariamente as práticas estabelecidas nos regulamentos da respectiva listagem. Os principais segmentos especiais de listagem do mercado de ações são o Novo Mercado, Nível 2, Nível 1. Já o Nível Básico compreende a não adesão a quaisquer dos segmentos mencionados (BM\&FBOVESPA, 2017). O Quadro 1 mostra algumas das diferenças requeridas pelas firmas ao aderirem aos segmentos de listagem.

Quadro 1 - Comparativo dos segmentos de listagem

\begin{tabular}{|l|c|c|c|c|}
\hline \multicolumn{1}{|c|}{ Aspectos } & Novo Mercado & Nível 2 & Nível 1 & Básico \\
\hline Ações & Apenas ON & $\begin{array}{c}\text { ON e PN (direitos } \\
\text { adicionais) }\end{array}$ & $\begin{array}{c}\text { ON e PN } \\
\text { (legislação) }\end{array}$ & $\begin{array}{c}\text { ON e PN } \\
\text { (legislação) }\end{array}$ \\
\hline Free float & Mínimo de 25\% & Mínimo de 25\% & Mínimo de 25\% & Não há regra \\
\hline Distribuição de ações & $\begin{array}{c}\text { Esforço para } \\
\text { dispersão acionária }\end{array}$ & $\begin{array}{c}\text { Esforço para } \\
\text { dispersão acionária }\end{array}$ & $\begin{array}{c}\text { Esforço para } \\
\text { dispersão acionária }\end{array}$ & Não há regra \\
\hline $\begin{array}{l}\text { Composição do } \\
\text { conselho }\end{array}$ & $\begin{array}{c}\text { Mínimo 5 membros; } \\
20 \% \text { independente; } \\
\text { mandato de 2 anos }\end{array}$ & $\begin{array}{c}\text { Mínimo 5 membros; } \\
20 \% \text { independente; } \\
\text { mandato de 2 anos }\end{array}$ & $\begin{array}{c}\text { Mínimo 3 membros } \\
\text { (legislação); } \\
\text { mandato de 2 anos }\end{array}$ & $\begin{array}{c}\text { Mínimo } 3 \\
\text { membros } \\
\text { (legislação) }\end{array}$ \\
\hline Acumulação de cargos & $\begin{array}{c}\text { Presidente do } \\
\text { conselho e diretor } \\
\text { presidente não são } \\
\text { os mesmos }\end{array}$ & $\begin{array}{c}\text { Presidente do } \\
\text { conselho e diretor } \\
\text { presidente não são } \\
\text { os mesmos }\end{array}$ & $\begin{array}{c}\text { Presidente do } \\
\text { conselho e diretor } \\
\text { presidente não são } \\
\text { os mesmos }\end{array}$ & Não há regra \\
\hline $\begin{array}{l}\text { Demonstrações } \\
\text { contábeis }\end{array}$ & $\begin{array}{c}\text { Traduzidas para o } \\
\text { inglês }\end{array}$ & $\begin{array}{c}\text { Traduzidas para o } \\
\text { inglês }\end{array}$ & $\begin{array}{c}\text { Conforme a } \\
\text { legislação }\end{array}$ & $\begin{array}{c}\text { Conforme a } \\
\text { legislação }\end{array}$ \\
\hline Reunião pública anual & Obrigatória & Obrigatória & Obrigatória & Facultativa \\
\hline Divulgação adicional & $\begin{array}{c}\text { Política de } \\
\text { negociação de }\end{array}$ & $\begin{array}{c}\text { Política de } \\
\text { negociação de }\end{array}$ & $\begin{array}{c}\text { Política de } \\
\text { negociação de }\end{array}$ & Não há regra \\
\hline
\end{tabular}




\begin{tabular}{|l|c|c|c|c|} 
& $\begin{array}{c}\text { valores e mobiliários } \\
\text { e código de conduta }\end{array}$ & $\begin{array}{c}\text { valores e mobiliários } \\
\text { e código de conduta }\end{array}$ & $\begin{array}{c}\text { valores e mobiliários } \\
\text { e código de conduta }\end{array}$ & \\
\hline Tag along & $100 \%$ para ON & $100 \%$ para ON e PN & $\begin{array}{c}80 \% \text { para ON } \\
\text { (legislação) }\end{array}$ & $\begin{array}{c}80 \% \text { para ON } \\
\text { (legislação) }\end{array}$ \\
\hline
\end{tabular}

Fonte: Adaptado de BM\&FBovespa (2017).

Como se pode observar, empresas pertencentes ao Novo Mercado atendem a práticas de governança mais rígidas se comparadas aos Níveis 2, 1 e básico. Ressalta-se que recentemente foram criados outros segmentos de listagem, tais como o Bovespa Mais e o Bovespa Mais Nível 2, voltados às empresas que desejam acessar de modo gradual o mercado (BM\&FBOVESPA, 2017). Esta pesquisa não explora as firmas destes segmentos, sendo poucas suas participantes. Cicogna, Toneto Júnior e Valle (2007) evidenciam que a adesão ao novo mercado melhora a qualidade das informações fornecidas e ajuda a aumentar o grau de segurança nas informações oferecidas aos acionistas, possibilitando a captação de recursos com custos competitivos.

\subsection{Governança, Estrutura de Capital e a Teoria Pecking Order}

A pressuposição básica deste estudo considera que a governança corporativa surge como um mecanismo que tem como consequência atrair mais investidores em potencial, procurando transmitir transparência das informações fornecidas pela empresa investida. Dessa maneira este mecanismo possibilita ao investidor um maior grau de informações. Deve-se enumerar que a necessidade do aprimoramento da governança corporativa nas empresas surge como resposta ao problema de agência, que ocorre quando os executivos tomam decisões que não priorizam a maximização dos lucros dos acionistas e sim da sua utilidade pessoal (SILVEIRA, 2002).

Silveira, Perobelli e Barros (2008) defendem que a governança corporativa pode ser determinante expressivo da estrutura de capital e do grau de alavancagem financeira. Através de estudos empíricos eles investigaram a influência das práticas de Governança Corporativa das empresas sobre sua estrutura de capital e encontraram significativa influência, com sentido positivo. Para eles, as firmas que aderem às boas práticas de governança corporativa possuem condições mais vantajosas para captar recursos externos podendo assim influenciar nas decisões de financiamento.

De acordo com Laux (2006), em tese, as taxas desvantajosas deveriam estar presentes em créditos de longo prazo devido ao período estendido e por existirem maiores riscos. Mesmo que uma empresa, com má condição financeira, esteja disposta a arcar com altas taxas de juros, estas possuirão chances reduzidas de conseguir empréstimos com prazos superiores, porque não é provável que conseguirão linhas de crédito disponíveis.

David, Nakamura e Bastos (2009) corroboram o exposto quando explicam que, tendo como meta estabelecida obter um baixo nível de endividamento, firmas mais rentáveis utilizam 
menos recursos de terceiros. Para isso é preferível que a empresa possua uma folga financeira (financial slack), o que poderia diminuir o seu coeficiente de endividamento. Já nas empresas menos lucrativas, com a incapacidade de autofinanciamento, haveria tendência a alcançar um nível maior de endividamento.

As “desvantagens da utilização do capital de terceiros estão relacionadas com o grau de endividamento da empresa que aumenta os custos de captação, ou juros a serem pagos, pela menor taxa, e a credibilidade da empresa no mercado" (IQUIAPAZA; AMARAL; ARAÚJO, 2008 p. 162). Para Procianoy e Schnorrenberger (2004), as empresas que adotam práticas de governança corporativa e que apresentam maior concentração de propriedade, mostram aversão ao endividamento e risco financeiro. Por seu turno, Medeiros e Daher (2005) ressaltam que, devido às limitações do mercado brasileiro, a oferta de crédito para as empresas e a captação de recursos via mercado de ações se torna difícil, o que faz com que a teoria da hierarquização de fontes de financiamento (Pecking Order) seja assim aplicável às firmas brasileiras, pois a preferência das empresas brasileiras recai sobre o endividamento.

Conforme Myers (1984), as empresas obedecem a uma hierarquia, onde elas buscam por uma forma de funding para financiar suas atividades empresariais. Conhecida como a teoria de hierarquização de fontes de financiamento, ou como teoria pecking order, ela explica que as empresas recorrem inicialmente a recursos gerados internamente, seguidos pela emissão de dívida e, finalmente, pela emissão de ações novas. Essa ordem hierárquica é fundamental para a teoria, que não se sustenta se a emissão de novas ações fique em primeiro lugar. O ideal é que ela seja realizada como último recurso, devido ao custo de capital.

O modelo de pecking order parte da hipótese de que existe assimetria de informação entre os administradores das empresas e os acionistas. Estes podem ser lesados ao realizar um investimento por não possuírem total informação sobre a empresa. Os investidores, então, fixam um preço para as ações das firmas lançadas no mercado por um valor médio, podendo condenar as boas e premiar as más empresas (CAMPOS, 2008). Para Costa Filho et al. (2008), seguindo as observações da teoria do pecking order, quanto menor for a assimetria informacional, maior será o volume de recursos externos, o que pode ser alcançado com governança corporativa.

\subsection{Estudos Empíricos Anteriores e Hipótese}

Este trabalho tem como fundamentação teórica estudos empíricos semelhantes dentro do contexto da governança corporativa e sua relação com o capital de terceiros. Esses trabalhos buscam confirmar ou refutar hipóteses questionadas dentro do cenário estudado, como mostra o Quadro 2, destacando os objetivos e os resultados por eles estabelecidos e encontrados. 
Quadro 2 - Quadro de estudos empíricos

\begin{tabular}{|c|c|c|}
\hline Autoria & Objetivo da pesquisa & Principais resultados \\
\hline $\begin{array}{l}\text { Cicogna, Toneto } \\
\text { Júnior e Valle } \\
(2007)\end{array}$ & $\begin{array}{l}\text { "Verificar se a adesão a padrões } \\
\text { superiores de governança corporativa } \\
\text { possibilitou às empresas que a fizeram } \\
\text { ter maior acesso ao crédito e obter } \\
\text { prazos mais elevados" (p. 53). }\end{array}$ & $\begin{array}{l}\text { "Melhores práticas de governança } \\
\text { influenciaram positivamente o acesso à } \\
\text { dívida com o mercado financeiro e } \\
\text { contribuíram para o alongamento do prazo } \\
\text { do passivo" (p. 62). }\end{array}$ \\
\hline $\begin{array}{c}\text { Scarpin, Macohon e } \\
\text { Dallabona (2013) }\end{array}$ & $\begin{array}{l}\text { "Analisar se há variabilidade nos índices } \\
\text { de endividamento em relação à adição } \\
\text { dos passivos contingentes no grupo do } \\
\text { passivo não circulante" (p. 3). }\end{array}$ & $\begin{array}{l}\text { "Os resultados demonstram diferenças } \\
\text { estatísticas significativas da variabilidade } \\
\text { dos quatro índices analisados" (p. 12). }\end{array}$ \\
\hline $\begin{array}{l}\text { Barros, Silva e } \\
\text { Voese (2013) }\end{array}$ & $\begin{array}{l}\text { "Examinar a relação entre atributo de } \\
\text { Governança Corporativa e custo de } \\
\text { endividamento, decorrente de } \\
\text { financiamentos, em empresas brasileiras } \\
\text { listadas na BM\&F Bovespa" (p. 9). }\end{array}$ & $\begin{array}{l}\text { "A adoção de mecanismos de Governança } \\
\text { pode exercer impacto sobre a redução do } \\
\text { custo de financiamento de dívidas de curto } \\
\text { e longo prazo no mercado brasileiro" (p. } \\
\text { 7). }\end{array}$ \\
\hline $\begin{array}{l}\text { Moura, Alves e } \\
\text { Luna (2013) }\end{array}$ & $\begin{array}{l}\text { "Analisar a relação entre endividamento } \\
\text { e rentabilidade, liquidez e retorno sobre } \\
\text { capital próprio, a partir da investigação } \\
\text { da existência de correlação e coeficientes } \\
\text { de regressão, sejam eles positivos ou } \\
\text { negativos" (p. 4). }\end{array}$ & $\begin{array}{l}\text { "Foi observada a tendência de correlação } \\
\text { negativa e pouco significativa entre } \\
\text { retorno e endividamento, que vem apoiar } \\
\text { os argumentos desenvolvidos pela teoria } \\
\text { do pecking order" (p. 1). }\end{array}$ \\
\hline $\begin{array}{c}\text { Bezerra e } \\
\text { Apolinário (2014) }\end{array}$ & $\begin{array}{l}\text { "Analisar a possível relação entre o nível } \\
\text { de endividamento das empresas e a } \\
\text { adoção de práticas de Governança } \\
\text { Corporativa" (p. 3). }\end{array}$ & $\begin{array}{l}\text { "Adesão aos níveis diferenciados de } \\
\text { governança corporativa provoca mudanças } \\
\text { nos níveis de endividamento das empresas } \\
\text { em relação às empresas listadas no } \\
\text { mercado tradicional" (p. 13). }\end{array}$ \\
\hline $\begin{array}{l}\text { Marques et al. } \\
\quad(2015)\end{array}$ & $\begin{array}{l}\text { "O objetivo do presente estudo foi } \\
\text { analisar a relação entre os níveis de } \\
\text { governança e a política de dividendos, } \\
\text { nível de endividamento e valor de } \\
\text { mercado de uma amostra de } 39 \text { empresas } \\
\text { participantes dos níveis } 1,2 \text { e Novo } \\
\text { Mercado" (p. 4). }\end{array}$ & $\begin{array}{l}\text { "Os resultados evidenciam existir } \\
\text { diferenças estatisticamente significativas } \\
\text { entre os grupos nas comparações entre os } \\
\text { mesmos para o nível de endividamento, Q } \\
\text { de Tobin e índice payout coerentemente } \\
\text { com as teorias vigentes" (p. } 4 \text { ). }\end{array}$ \\
\hline $\begin{array}{l}\text { Costa Filho et al. } \\
\text { (2016) }\end{array}$ & $\begin{array}{l}\text { "Verificar a relação entre endividamento } \\
\text { e qualidade da governança corporativa. } \\
\text { Adicionalmente, pretende-se revisar as } \\
\text { principais teorias referentes à estrutura } \\
\text { de capital (Trade-off e Pecking Order)" } \\
\text { (p. 2). }\end{array}$ & $\begin{array}{l}\text { "Nas duas metodologias adotadas, os } \\
\text { resultados mostraram-se semelhantes, } \\
\text { evidenciando, nas empresas da amostra, } \\
\text { uma correlação negativa entre o } \\
\text { endividamento e a qualidade da } \\
\text { governança corporativa" (p. 1). }\end{array}$ \\
\hline
\end{tabular}

Fonte: Elaborado pelo autor com base na revisão da literatura.

Barros, Silva e Voese (2015) evidenciam que diversos estudos enfatizam que a presença de mecanismos de governança corporativa pode exercer efeito significativo sobre a redução dos custos de financiamentos de capitais de terceiros, podendo assumir importância na qualidade da estrutura de capital das empresas. Através dos resultados obtidos em sua pesquisa, não foi possível afirmar que a adesão aos níveis elevados de governança corporativa seja capaz de obter custos menores na captação de recursos. Bezerra e Apolinário (2014) concluíram que a adesão aos níveis diferenciados afeta o endividamento. Enquanto que Cicogna, Toneto Júnior e Valle (2007) concluíram que a adoção de boas práticas de governança corporativa pode aumentar a captação de recursos. Eles ainda afirmam que a restrição de crédito poderá ser menor à medida que as estruturas e padrões de governança corporativa são aprimorados. 
Mediante a revisão teórica apresentada e tendo como base o grupo estudado, este estudo levanta as seguintes hipóteses:

H1: A adesão aos melhores níveis de governança corporativa possui relação com a estrutura de capital das empresas;

H2: Existe uma relação entre a qualidade de governança corporativa e a estrutura de capital das empresas.

\section{PROCEDIMENTOS METODOLÓGICOS}

Tendo em vista seu objetivo principal, a pesquisa, define-se como descritiva. Segundo Malhotra (2009), os estudos descritivos são aqueles que descrevem em um nível de detalhes maior as características e os comportamentos de fenômenos associados às variáveis estudadas, geralmente induzindo o teste de hipóteses a partir de estudos prévios. Quanto aos meios, todo o levantamento de dados deu-se por meio de pesquisa documental (LAKATOS; MARCONI, 2009), realizado a partir das demonstrações financeiras e formulários de referência das firmas, buscados no endereço eletrônico da BM\&FBovespa e da Comissão de Valores Mobiliários (CVM). Quanto à sua abordagem, esta investigação é tomada como quantitativa, porque como consta em Sampieri, Collado e Lucio (2013), a pesquisa quantitativa usa a coleta de dados para testar hipóteses com base na medição numérica e na análise estática para estabelecer padrões de comportamento.

A população da pesquisa foi constituída pelas 100 maiores empresas de capital aberto, conforme a Revista Exame Melhores \& Maiores, edição de 2016. Desse universo, excluíramse 18 firmas do setor financeiro, que, para Medeiros e Daher (2005), possuem características próprias, principalmente no que diz respeito à composição de endividamento, o que causaria viés nos resultados deste estudo. Das 82 empresas restantes, uma foi excluída devido à ausência de dados nas bases secundárias de coleta. Outras 4 firmas consideradas outliers também foram retiradas, pois apresentavam valores discrepantes do conjunto da amostra, permanecendo na análise 77 firmas, distribuídas em diferentes segmentos de listagem, como mostra o Quadro 3.

Quadro 3 - Amostra da pesquisa

\begin{tabular}{lrr}
\hline Segmento de listagem & \multicolumn{2}{c}{ Empresas } \\
\hline Novo Mercado (NM) & 43 & $56 \%$ \\
Nível 2 (N2) & 5 & $6 \%$ \\
Nível 1 (N1) & 11 & $14 \%$ \\
Nível Básico (NB) & 18 & $23 \%$ \\
Total & 77 & $100 \%$ \\
\hline Fonte: Dados da pesquisa. & &
\end{tabular}

A partir da revisão tomada no referencial teórico deste estudo, foram definidas medidas que representassem a governança corporativa. A primeira das medidas refere-se aos segmentos 
diferenciados da BM\&FBovespa, conforme o Quadro 1. Esta medida é ordinal, sendo assumido valor "1" para empresas do Nível Básico; valor "2" para empresas dos Níveis 2 e 1; e valor "3" para empresas do Novo Mercado, em função do nível de governança corporativa. Os segmentos são considerados como variável no estudo de Lima et al. (2015).

A segunda medida adotada é o Índice de Qualidade da Governança Corporativa (IQGC), adaptado de Lameira e Ness Júnior (2011), utilizado recentemente por Santos, Vasconcelos e De Luca (2015). O IQGC é composto por 5 dimensões que dispõem de proxies relacionadas à governança, totalizando 14 variáveis que são utilizadas para sua construção. Todas elas são binárias que indicam afirmação (1 escore) ou negação (nenhum escore) de cada sentença em todas as firmas analisadas, de forma semelhante a Cunha e Politelo (2013). O IQGC é obtido a partir dos escores obtidos pela firma divididos pela pontuação total possível (14 escores), em termos percentuais. Todas as variáveis do índice são apresentadas no Quadro 4.

Quadro 4-Definição das dimensões e variáveis da governança corporativa

\begin{tabular}{|c|c|c|c|c|}
\hline \multicolumn{2}{|c|}{ Dimensão } & \multirow{2}{*}{$\begin{array}{l}\text { Variável } \\
\text { Participação do } \\
\text { controlador }\end{array}$} & \multirow{2}{*}{$\begin{array}{l}\text { Definição } \\
\text { O controlador (ou grupo controlador) } \\
\text { possui menos de } 50 \% \text { das ações } \\
\text { ordinárias }\end{array}$} & \multirow{2}{*}{$\begin{array}{l}\text { Dados } \\
\begin{array}{l}\text { No formulário de referência } \\
\text { em posição acionária }\end{array}\end{array}$} \\
\hline 1 & Estrutura de & & & \\
\hline 1 & $\begin{array}{l}\text { propriedade e } \\
\text { controle }\end{array}$ & $\begin{array}{l}\% \text { de ações } \\
\text { preferenciais }\end{array}$ & $\begin{array}{l}\text { O percentual de ações preferenciais é } \\
\text { inferior a } 20 \% \text { do total do capital }\end{array}$ & $\begin{array}{l}\text { No formulário de referência } \\
\text { em Capital social/ } \\
\text { Informações - capital social }\end{array}$ \\
\hline \multirow{2}{*}{2} & \multirow{2}{*}{$\begin{array}{l}\text { Ambiente } \\
\text { institucional }\end{array}$} & Níveis de GC & $\begin{array}{l}\text { A empresa participa dos níveis } \\
\text { diferenciados de governança } \\
\text { corporativa da BM\&FBovespa }\end{array}$ & $\begin{array}{l}\text { Verificou-se o segmento de } \\
\text { listagem apresentação } \\
\text { inicial das empresas listadas }\end{array}$ \\
\hline & & Emissão de ADR & $\begin{array}{l}\text { A empresa é emissora de American } \\
\text { Depositary Receipt (ADR) }\end{array}$ & $\begin{array}{l}\text { No banco de dados do JP } \\
\text { Morgan's ADR } \\
\text { https://www.adr.com/ }\end{array}$ \\
\hline \multirow{3}{*}{3} & \multirow{3}{*}{$\begin{array}{l}\text { Auditoria e } \\
\text { conselho fiscal }\end{array}$} & Auditoria Líder & $\begin{array}{l}\text { As demonstrações do período foram } \\
\text { auditadas por uma Bigfour (Price, } \\
\text { KPMG, Delloite, Ernst \& Young) }\end{array}$ & $\begin{array}{l}\text { No formulário de referência } \\
\text { em auditores } \\
\text { independentes; } \\
\text { identificação e remuneração }\end{array}$ \\
\hline & & $\begin{array}{l}\text { Parecer da } \\
\text { Auditoria }\end{array}$ & $\begin{array}{l}\text { Não houve parecer da auditoria com } \\
\text { discordância de opinião/ressalva nas } \\
\text { demonstrações financeiras } \\
\text { padronizadas }\end{array}$ & $\begin{array}{l}\text { Em demonstrações } \\
\text { financeiras padronizadas, } \\
\text { nos pareceres e declarações } \\
\text { em parecer dos auditores } \\
\text { independentes }\end{array}$ \\
\hline & & Conselho Fiscal & $\begin{array}{l}\text { A empresa possui conselho fiscal } \\
\text { permanente }\end{array}$ & $\begin{array}{l}\text { No formulário de } \\
\text { referência; assembleia e } \\
\text { administração }\end{array}$ \\
\hline \multirow[b]{2}{*}{4} & \multirow[b]{2}{*}{$\begin{array}{l}\text { Conselho de } \\
\text { administração e } \\
\text { constituição de } \\
\text { comitês }\end{array}$} & $\begin{array}{l}\text { Participação nos } \\
\text { lucros }\end{array}$ & $\begin{array}{l}\text { Os administradores possuem } \\
\text { participação nos lucros }\end{array}$ & $\begin{array}{l}\text { No formulário de referência } \\
\text { em remuneração dos } \\
\text { administradores }\end{array}$ \\
\hline & & Tamanho & $\begin{array}{l}\text { O conselho de administração possui } \\
\text { entre } 5 \text { e } 9 \text { membros }\end{array}$ & $\begin{array}{l}\text { No formulário de } \\
\text { referência; assembleia e } \\
\text { administração, composição } \\
\text { e experiência profissional } \\
\text { da administração e do } \\
\text { conselho fiscal }\end{array}$ \\
\hline
\end{tabular}




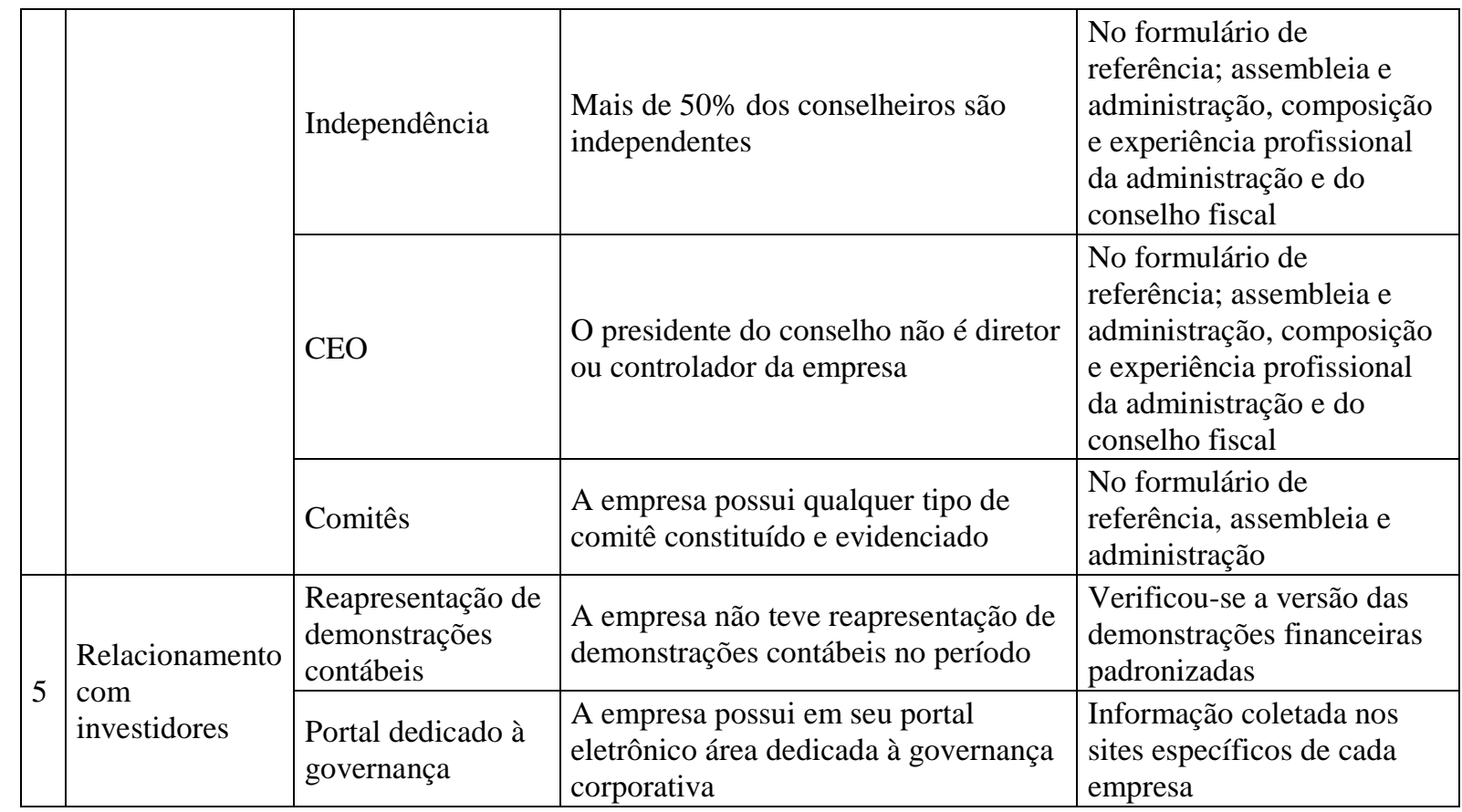

Fonte: Adaptado de Lameira e Ness Júnior (2011) e Cunha e Politelo (2013).

Como medidas da estrutura de capital, foram considerados aspectos do endividamento e da dependência financeira das empresas, como mostra o Quadro 5.

Quadro 5 - Variáveis consideradas para análise da estrutura de capital das firmas

\begin{tabular}{|c|c|c|c|c|c|}
\hline Medidas & Definição & Variáveis & Equação & Dados & Base Teórica \\
\hline \multirow{3}{*}{ Endividamento } & \multirow{3}{*}{$\begin{array}{l}\text { Proporção } \\
\text { do capital de } \\
\text { terceiros em } \\
\text { relação ao } \\
\text { capital } \\
\text { próprio }\end{array}$} & $\begin{array}{l}\text { Total } \\
\text { (End) }\end{array}$ & $\begin{array}{l}\text { Passivo Exigível } \\
\text { Total/Patrimônio Líquido }\end{array}$ & $\begin{array}{l}\text { Balanço } \\
\text { Patrimonial }\end{array}$ & \multirow{6}{*}{$\begin{array}{l}\text { Assaf Neto } \\
\text { (2010); } \\
\text { Fonseca, } \\
\text { Silveira e } \\
\text { Hiratuka } \\
\text { (2016); Bezerra } \\
\text { e Apolinário } \\
\text { (2014); } \\
\text { Scarpin, } \\
\text { Macohon e } \\
\text { Dallabona } \\
\text { (2013); Costa } \\
\text { Filho et al. } \\
\text { (2016) }\end{array}$} \\
\hline & & $\begin{array}{l}\text { De curto prazo } \\
\text { (EndCp) }\end{array}$ & $\begin{array}{l}\text { Passivo Exigível } \\
\text { Circulante/Patrimônio Líquido }\end{array}$ & $\begin{array}{l}\text { Balanço } \\
\text { Patrimonial }\end{array}$ & \\
\hline & & $\begin{array}{l}\text { De Longo } \\
\text { Prazo (EndLp) }\end{array}$ & $\begin{array}{l}\text { Passivo Exigível Não } \\
\text { Circulante/Patrimônio Líquido }\end{array}$ & $\begin{array}{l}\text { Balanço } \\
\text { Patrimonial }\end{array}$ & \\
\hline \multirow{3}{*}{$\begin{array}{l}\text { Dependência } \\
\text { Financeira }\end{array}$} & \multirow{3}{*}{$\begin{array}{l}\text { Proporção } \\
\text { de ativos } \\
\text { financiada } \\
\text { por capital } \\
\text { oriundo de } \\
\text { terceiros }\end{array}$} & $\begin{array}{l}\text { Total } \\
\text { (Df) }\end{array}$ & $\begin{array}{l}\text { Passivo Exigível Total/Ativo } \\
\text { Total }\end{array}$ & $\begin{array}{l}\text { Balanço } \\
\text { Patrimonial }\end{array}$ & \\
\hline & & $\begin{array}{l}\text { De curto prazo } \\
(\mathrm{DfCp})\end{array}$ & $\begin{array}{l}\text { Passivo Exigível } \\
\text { Circulante/Ativo Total }\end{array}$ & $\begin{array}{l}\text { Balanço } \\
\text { Patrimonial } \\
\end{array}$ & \\
\hline & & $\begin{array}{l}\text { De Longo } \\
\text { Prazo (DfLp) }\end{array}$ & $\begin{array}{l}\text { Passivo Exigível Não } \\
\text { Circulante/Ativo Total }\end{array}$ & $\begin{array}{l}\text { Balanço } \\
\text { Patrimonial }\end{array}$ & \\
\hline
\end{tabular}

Fonte: Elaborado pelo autor com base na revisão da literatura.

A partir dessas variáveis foram realizadas as análises descritivas e de correlação. Assim, buscou-se verificar se a participação nos segmentos de listagem e o IQGC tinham relação com a estrutura de capital das firmas, medida através do endividamento e da dependência financeira. A análise de correlação foi efetuada com auxílio do software estatístico Statistical Package for the Social Sciences (SPSS).

\section{APRESENTAÇÃO, ANÁLISE E DISCUSSÃO DOS RESULTADOS}

Os resultados são iniciados a partir da Tabela 2, que apresenta a estatística descritiva do Índice de Qualidade da Governança Corporativa (IQGC), bem como de suas dimensões. 
Tabela 2 - Análise descritiva do IGQG e suas dimensões

\begin{tabular}{lrrrrrr}
\hline \multicolumn{1}{c}{ Medidas } & IGQC & Dimensão 1 & Dimensão 2 & Dimensão 3 & Dimensão 4 & Dimensão 5 \\
\hline Média & $64 \%$ & $68 \%$ & $50 \%$ & $73 \%$ & $54 \%$ & $86 \%$ \\
Desv. Pad. & $13 \%$ & $30 \%$ & $29 \%$ & $17 \%$ & $19 \%$ & $24 \%$ \\
Coef. Var. & $21 \%$ & $44 \%$ & $58 \%$ & $23 \%$ & $36 \%$ & $28 \%$ \\
Mediana & $64 \%$ & $50 \%$ & $50 \%$ & $67 \%$ & $60 \%$ & $100 \%$ \\
Mínimo & $29 \%$ & $0 \%$ & $0 \%$ & $33 \%$ & $0 \%$ & $0 \%$ \\
Máximo & $93 \%$ & $100 \%$ & $100 \%$ & $100 \%$ & $100 \%$ & $100 \%$ \\
\hline
\end{tabular}

Fonte: Dados da pesquisa.

A análise do IGQC indica, através da sua mediana, que metade das firmas tem até $64 \%$ de evidenciação com base nas variáveis de governança e a outra metade possui acima disso. O resultado máximo para o índice foi de 93\%, enquanto o valor mínimo foi de aproximadamente $29 \%$. Já o desvio padrão apresentado de $13 \%$ indica que as empresas apresentam variabilidade razoável no que tange a análise, logo entende-se que o resultado geral tende a estar próximo do valor esperado apresentado (média de 64\%). O resultado pode ser considerado satisfatório, pois, a amostra, em sua maioria, atende a mais da metade dos itens de governança considerados pela pesquisa. Assim como nesta análise, Cunha e Politelo (2013) obtiveram resultados de empresas que não atenderam a todos os mecanismos de governança, com pontuação máxima de 94,62\%.

Acerca das dimensões, é possível verificar a existência de empresas que não atendem a quaisquer dos critérios estabelecidos na Dimensão 1, o que indica concentração acionária nas empresas. Ressalta-se que a Dimensão 5, que trata do relacionamento com investidores, obteve melhores resultados de forma geral na análise descritiva, indicando maior comprometimento das firmas com a comunicação entre empresa e stakeholders. Santos, Vasconcelos e De Luca (2015) também obtiveram elevado nível de atendimento nesta dimensão. Em contrapartida, a Dimensão 2 apresentou a menor média, demandando mais atenção ao ambiente institucional (Brasil e Estados Unidos) por parte dessas empresas. Através do coeficiente de variação, temse maior homogeneidade dos índices na Dimensão 3, que trata da assessoria da auditoria e da fiscalização do conselho fiscal. Isso mostra como as firmas estão preocupadas com a auditoria e alguns órgãos da gestão. A Dimensão 4 apresenta a segunda menor média (54\%); dessa forma é possível verificar que tais firmas poderiam atender melhor às práticas relacionas ao conselho de administração e constituição dos comitês, merecendo, portanto, mais atenção.

$\mathrm{Na}$ Tabela 3 pode-se verificar a frequência com que as firmas são apresentadas de acordo com a variável da dimensão da governança corporativa.

Tabela 3 - Frequência de identificação das variáveis de governança corporativa

\begin{tabular}{clll}
\hline Dimensão & \multicolumn{1}{c}{ Aspecto } & \multicolumn{2}{c}{ Empresas } \\
\hline \multirow{2}{*}{1} & Participação do controlador & 34 & $44 \%$ \\
& Parcela de ações preferenciais & 71 & $92 \%$ \\
\hline \multirow{2}{*}{2} & Níveis de GC & 60 & $78 \%$
\end{tabular}




\begin{tabular}{llrr}
\hline & Emissão de ADR & 17 & $22 \%$ \\
\hline \multirow{2}{*}{3} & Auditoria (Big four) & 72 & $94 \%$ \\
& Parecer da auditoria & 72 & $94 \%$ \\
& Conselho fiscal & 25 & $32 \%$ \\
\hline \multirow{2}{*}{4} & Participação nos lucros & 4 & $5 \%$ \\
& Tamanho do conselho & 57 & $74 \%$ \\
& Independência & 18 & $23 \%$ \\
& CEO & 70 & $91 \%$ \\
& Comitês diversos & 59 & $77 \%$ \\
\hline \multirow{2}{*}{5} & Reapresentação de demonstrações & 58 & $75 \%$ \\
& Portal institucional para a governança & 75 & $97 \%$ \\
\hline
\end{tabular}

Fonte: Dados da pesquisa.

Observa-se que na Dimensão 4, apenas quatro firmas atendem à prática de governança que enfatiza que os administradores devem possuir participação nos lucros, correspondente a apenas 5\% das firmas analisadas. A referida evidência também pode ser observada no estudo de Santos, Vasconcelos e De Luca (2015) em que há uma ausência de incentivos de alinhamento de interesses em relação a participação dos administradores no lucro. Isto corrobora a hipótese de Silveira (2002) quando diz que este mecanismo assume um papel mais figurativo do que profissional na maioria das empresas. Também é possível constatar, com a Dimensão 3, que as empresas possuem preocupação com a fidedignidade e transparência das informações, sendo 94\% das empresas auditadas por uma Big Four. Quanto ao parecer da auditoria, verifica-se que a maioria das firmas apresentam um parecer sem qualquer ressalva, indicando que a auditoria está convencida de todos os aspectos tratados quanto à confiabilidade das informações.

$\mathrm{Na}$ Dimensão 2, que trata do ambiente institucional, percebe-se que apenas $22 \%$ das empresas optaram por negociar ações fora do país através da emissão de American Depositary Receipt (ADR). Lameira e Ness Júnior (2011) sugerem que as empresas que possuem melhores práticas de governança corporativa podem aumentar a quantidade de investidores através da emissão de ADR. O resultado obtido nesta dimensão específica diverge dos obtidos por Santos, Vasconcelos e De Luca (2015) que estudaram a internacionalização e a governança nas maiores companhias de capital aberto do Brasil. Em sua análise, foi possível verificar que mais de 50\% das empresas eram emissoras de ADR. A diferença dos resultados pode se dar tanto em relação ao tamanho da amostra estudada (99 empresas), quanto em relação ao período da coleta desta pesquisa (setembro e outubro de 2013). Deve-se reforçar que no presente estudo foram tomadas apenas as empresas da NYSE (Bolsa de Valores de Nova Iorque).

A Tabela 4 apresenta uma análise descritiva geral da estrutura de capital das empresas com base nas variáveis de endividamento e dependência financeira calculadas no estudo, tanto de maneira geral, quanto no curto e no longo prazo. 
Tabela 4 - Análise descritiva da estrutura de capital

\begin{tabular}{lrrrrrr}
\hline Variáveis & Média & Desv. Pad. & Coef. Var. & Mediana & Mínimo & Máximo \\
\hline End & 1,71 & 1,14 & $67 \%$ & 1,39 & 0,16 & 5,97 \\
EndCp & 0,63 & 0,46 & $74 \%$ & 0,50 & 0,08 & 2,59 \\
EndLp & 1,08 & 0,82 & $76 \%$ & 0,89 & 0,03 & 3,96 \\
\hline Df & 0,57 & 0,15 & $27 \%$ & 0,58 & 0,14 & 0,86 \\
DfCp & 0,22 & 0,10 & $47 \%$ & 0,21 & 0,05 & 0,55 \\
DfLp & 0,36 & 0,15 & $41 \%$ & 0,38 & 0,02 & 0,71 \\
\hline
\end{tabular}

Fonte: Dados da pesquisa.

Com base na Tabela 4, percebe-se que as firmas possuem em média um endividamento de 1,71. Assim é possível verificar que a dívida está mais alocada no capital de terceiros do que no capital próprio, o que explica o maior grau de dependência financeira $(0,57)$. Nota-se que os limites de dependência financeira analisados pela média chegam a valores máximos de $86 \%$ (maior participação de passivos financiando os ativos) e mínimos de 14\%, (maior participação de recursos próprios financiando os ativos). As análises por vencimento (curto e longo prazos) denotam que essas empresas concentram maior parte das dívidas em períodos superiores a um ano da data de encerramento do exercício contábil (1,08 - EndLp; 0,36 - DfLp).

Verifica-se além que o menor valor obtido pela variável de endividamento foi de $16 \%$. Pode-se interpretar, nesse caso, o Patrimônio Líquido como principal fonte de financiamento das empresas. Nesses casos há reforço à teoria pecking order que sugere que a emissão de ações deve ser captada como último recurso, devido aos custos de obtenção de recursos. Moura, Alves e Luna (2013) também obtiveram resultados que apoiam a teoria pecking order, considerando esta teoria mais consistente para explicar o comportamento da estrutura de capital das firmas estudadas.

Na Tabela 5 nota-se a comparação dos índices de endividamento em cada segmento de listagem de governança corporativa da BM\&FBovespa.

Tabela 5 - Endividamento nos segmentos de governança corporativa

\begin{tabular}{|c|c|c|c|c|c|c|c|c|}
\hline Variáveis & Segmentos & Empresas & Média & Desv. Pad. & Coef. Var. & Mediana & Mínimo & Máximo \\
\hline \multirow{3}{*}{ End } & NM & 43 & 1,5226 & 0,9708 & $64 \%$ & 1,3167 & 0,1639 & 4,5537 \\
\hline & N1 e N2 & 16 & 1,7443 & 1,1817 & $68 \%$ & 1,3769 & 0,3307 & 4,5760 \\
\hline & Básico & 18 & 2,8615 & 2,3813 & $83 \%$ & 2,4898 & 0,4830 & 5,9738 \\
\hline \multirow{3}{*}{ EndCp } & NM & 43 & 0,5578 & 0,3907 & $70 \%$ & 0,4535 & 0,0942 & 1,9126 \\
\hline & N1 e N2 & 16 & 0,5698 & 0,4983 & $87 \%$ & 0,4279 & 0,0766 & 1,8928 \\
\hline & Básico & 18 & 0,8983 & 0,9552 & $106 \%$ & 0,5988 & 0,2622 & 2,5880 \\
\hline \multirow{3}{*}{ EndLp } & NM & 43 & 0,9648 & 0,6464 & $67 \%$ & 0,8536 & 0,0284 & 2,7434 \\
\hline & N1 e N2 & 16 & 1,1745 & 0,9216 & $78 \%$ & 0,8705 & 0,2541 & 3,3170 \\
\hline & Básico & 18 & 1,9632 & 1,7456 & $89 \%$ & 2,0573 & 0,1927 & 3,9595 \\
\hline
\end{tabular}

Fonte: Dados da pesquisa.

Conforme análise obtida pela média, na Tabela 5, aparentemente as empresas do nível básico são as mais endividadas, tanto na variável do endividamento geral $(2,86)$, quanto a curto 
prazo $(0,89)$ e a longo prazo $(1,96)$, podendo isto comprometer a liquidez dessas empresas. Este resultado corrobora com o estudo feito por Bezerra e Apolinário (2014), que verificaram que o segmento básico apresentou maiores médias de endividamento. Já as firmas do Novo Mercado possuem menores médias de endividamento geral $(1,5226)$, de curto prazo $(0,5578)$ e de longo prazo (0,9648). Ao que parece, há uma relação negativa entre o endividamento e a adesão a maiores níveis de governança. Pode-se ainda verificar que as empresas do Novo mercado têm média de endividamento maior no longo prazo do que no curto prazo, logo possuem mais tempo para a quitação de suas dívidas.

Foi possível observar que as empresas que estão no novo mercado possuem uma média de endividamento menor se comparada àquelas dos outros segmentos, sugerindo que poderia haver uma relação negativa entre governança e endividamento. Isto seria coerente pois firmas com maior nível de governança poderiam ser mais atrativas para os investidores, pretendendo administrar melhor seu endividamento.

Na Tabela 6 é possível verificar a parcela dos ativos financiadas pelo capital de terceiros em comparação a cada segmento da governança corporativa.

Tabela 6 - Dependência financeira nos segmentos de governança corporativa

\begin{tabular}{clccrrrrr}
\hline Variáveis & Segmentos & Empresas & Média & Desv. Pad. & Coef. Var. & Mediana & Mínimo & Máximo \\
\hline \multirow{3}{*}{ Df } & NM & 43 & 0,5504 & 0,1567 & $28 \%$ & 0,5683 & 0,1408 & 0,8199 \\
& N1 e N2 & 16 & 0,5787 & 0,1543 & $27 \%$ & 0,5787 & 0,2485 & 0,8207 \\
& Básico & 18 & 0,6261 & 0,1414 & $23 \%$ & 0,6303 & 0,3257 & 0,8566 \\
\hline \multirow{3}{*}{ DfCp } & NM & 43 & 0,2051 & 0,0809 & $39 \%$ & 0,2103 & 0,0471 & 0,3955 \\
& N1 e N2 & 16 & 0,1906 & 0,1263 & $66 \%$ & 0,1448 & 0,0575 & 0,5350 \\
& Básico & 18 & 0,2700 & 0,1085 & $40 \%$ & 0,2707 & 0,1095 & 0,5507 \\
\hline \multirow{3}{*}{ DfLp } & NM & 43 & 0,3453 & 0,1357 & $39 \%$ & 0,3706 & 0,0244 & 0,5718 \\
& N1 e N2 & 16 & 0,3881 & 0,1488 & $38 \%$ & 0,3772 & 0,1389 & 0,6759 \\
& Básico & 18 & 0,3561 & 0,1731 & $49 \%$ & 0,4008 & 0,0663 & 0,7110 \\
\hline
\end{tabular}

Fonte: Dados da pesquisa.

Segundo a Tabela 6, O Novo Mercado apresenta uma média de dependência financeira menor se comparado aos Níveis 2 e 1, sendo também menor que o nível básico. Aparentemente as empresas com maior nível de governança tem uma menor dependência financeira, ou seja, elas tendem a financiar os seus ativos com capital próprio, indicando que elas podem estar preocupadas em não se endividar. Este resultado contraria Cicogna et al. (2007), que obtiveram que melhores práticas de governança mostram ter influência positiva na captação de recursos financeiros, contribuindo com o alongamento do prazo dos passivos. Por outro lado, notou-se a concentração das dívidas no longo prazo, corroborando parcialmente o referido estudo.

Na Tabela 7 é possível verificar a correlação da governança corporativa e estrutura de capital das firmas estudadas. 
Governança corporativa e estrutura de capital nas maiores empresas de capital aberto à luz da teoria pecking order

Tabela 7 - Análise de correlação: governança corporativa e estrutura de capital

\begin{tabular}{llcccccr}
\hline \multicolumn{2}{c}{ Governança Corporativa } & End & EndCp & EndLp & Df & DfCp & \multicolumn{1}{c}{ DfLp } \\
\hline \multirow{2}{*}{ Segmentos de listagem } & Correlação & $\mathbf{- 0 , 1 9 2}$ & $\mathbf{- 0 , 2 2 6}$ & $-0,098$ & $\mathbf{- 0 , 1 9 2}$ & $-0,161$ & $-0,047$ \\
& Sig. & $\mathbf{0 , 0 9 4} *$ & $\mathbf{0 , 0 4 8} * *$ & 0,394 & $\mathbf{0 , 0 9 4}$ & 0,163 & \multicolumn{1}{c}{0,688} \\
\hline \multirow{2}{*}{ IQGC } & Correlação & $-0,149$ & $-0,184$ & $-0,074$ & $-0,149$ & $-0,134$ & 0,001 \\
& Sig. & 0,195 & 0,110 & 0,521 & 0,195 & 0,246 & 0,995 \\
\hline & Observações & $\mathbf{7 7}$ & $\mathbf{7 7}$ & $\mathbf{7 7}$ & $\mathbf{7 7}$ & $\mathbf{7 7}$ & $\mathbf{7 7}$ \\
\hline
\end{tabular}

Nota: ** Significante a 5\%; *Significante a $10 \%$

Fonte: Dados da pesquisa.

Nota-se, a partir da Tabela 7, uma correlação moderada de 19,20\%, com significância de $10 \%$, entre o segmento de listagem e o endividamento (a mesma correlação é observada em relação à dependência financeira). Com $95 \%$ de certeza, pode-se afirmar que há uma correlação negativa de 22,6\% entre segmento de listagem e endividamento de curto prazo. Tais resultados ratificam as evidências expostas nas Tabelas 4 e 5, que sinalizavam haver relação negativa entre a governança corporativa e a estrutura de capital dessas empresas. Logo, confirma-se a hipótese $\mathrm{H}_{1}$, indicando existir relação entre as variáveis. Entende-se, portanto, que quanto maior o nível de segmentos da governança menor o endividamento (geral e de curto prazo) e a dependência financeira (geral). Resultado similar foi observado nos trabalhos de Costa filho et al. (2008) e Bezerra e Apolinário (2014). Verifica-se além que não há relação entre o IQGC e as variáveis de endividamento e dependência financeira, refutando-se assim a hipótese $\mathrm{H}_{2}$ que presumia a relação entre a qualidade da governança e a estrutura de capital.

A Tabela 8 dispõe as dimensões de governança correlacionadas à estrutura de capital (endividamento e dependência financeira) das firmas estudadas.

Tabela 8 - Análise de correlação: dimensões da governança corporativa e estrutura de capital

\begin{tabular}{llcccccc}
\hline \multicolumn{2}{c}{ Dimensões da Governança } & End & EndCp & EndLp & Df & \multicolumn{1}{c}{ DfCp } & \multicolumn{1}{c}{ DfLp } \\
\hline Dimensão 1 & Correlação & $\mathbf{- 0 , 2 7 3}$ & $-0,148$ & $\mathbf{- 0 , 2 5 4}$ & $\mathbf{- 0 , 2 7 3}$ & $-0,008$ & $\mathbf{- 0 , 2 5 3}$ \\
& Sig. & $\mathbf{0 , 0 1 6} * *$ & 0,198 & $\mathbf{0 , 0 2 6} * *$ & $\mathbf{0 , 0 1 6} * *$ & 0,942 & $\mathbf{0 , 0 2 6} * *$ \\
\hline Dimensão 2 & Correlação & 0,000 & $-0,175$ & 0,08 & 0,000 & $-0,244$ & 0,168 \\
& Sig. & 1,000 & 0,128 & 0,487 & 1,000 & $\mathbf{0 , 0 3 2 * *}$ & 0,144 \\
\hline Dimensão 3 & Correlação & $-0,084$ & $-0,148$ & $-0,045$ & $-0,084$ & $-0,111$ & $-0,018$ \\
& Sig. & 0,468 & 0,200 & 0,700 & 0,468 & 0,335 & 0,875 \\
\hline Dimensão 4 & Correlação & 0,033 & 0,033 & 0,066 & 0,033 & 0,024 & 0,088 \\
& Sig. & 0,776 & 0,778 & 0,569 & 0,776 & 0,835 & 0,448 \\
\hline Dimensão 5 & Correlação & $\mathbf{- 0 , 1 9 2}$ & $\mathbf{- 0 , 2 9 2}$ & $-0,035$ & $\mathbf{- 0 , 1 9 2}$ & $\mathbf{- 0 , 2 8 2}$ & 0,069 \\
& Sig. & $\mathbf{0 , 0 9 4 *}$ & $\mathbf{0 , 0 1 0} * *$ & 0,761 & $\mathbf{0 , 0 9 4 *}$ & $\mathbf{0 , 0 1 3} * *$ & 0,550 \\
\hline & $\mathbf{7 7}$ & $\mathbf{7 7}$ & $\mathbf{7 7}$ & $\mathbf{7 7}$ & $\mathbf{7 7}$ & $\mathbf{7 7}$ \\
\hline
\end{tabular}

Nota: ** Significante a 5\%; * Significante a $10 \%$

Fonte: Dados da pesquisa.

Entre a Dimensão 1, que trata de estrutura de propriedade e controle e o endividamento é possível observar uma correlação negativa de 27,30\%, ao nível de 5\%. Entende-se que uma menor concentração acionária e menos ações do tipo preferenciais denotam menor emprego de recursos nos passivos circulante e não circulante. Também são observadas as correlações com 
o endividamento de longo prazo de 25,40\%, ao nível de 5\%; dependência financeira total de $27,30 \%$, ao nível de 5\%, e dependência financeira no longo prazo de 25,30\%, ao nível de 5\%. Na Dimensão 2 foi possível observar uma correlação negativa de 24,40\%, ao nível de 5\%, na dependência financeira de curto prazo; ou seja, quão melhor for o ambiente institucional, menor será a participação de passivos financiando os seus investimentos a curto prazo. Na Dimensão 5 também há uma correlação negativa de 19,20\%, ao nível de 10\%, no endividamento geral e na dependência financeira geral. Há ainda a correlação negativa de $29,20 \%$, ao nível de 5\%, no endividamento de curto prazo e de 28,20\% com a dependência financeira de curto prazo. Esses resultados sugerem que uma menor concentração acionária, maior participação ao voto, melhor inserção da firma quanto às instituições de governança impostas no mercado e a otimização do relacionamento com o investidor levam as firmas a reduzir a participação de capital de terceiros. Aparentemente, a governança corporativa sinaliza aprimoramento da administração das fontes de recursos e concentração dos investimentos oriundos do capital próprio.

\section{CONCLUSÃO}

A pesquisa atingiu o seu objetivo de investigar a relação entre as práticas de governança e a estrutura de capital. Para atender a este objetivo foram realizadas análises descritivas e de correlação. Assim, buscou-se verificar se a participação nos segmentos de listagem e o índice de qualidade da governança corporativa tinham relação com a estrutura de capital das empresas, medida através do endividamento e da dependência financeira.

Com a análise descritiva, foram obtidos resultados que sugeriam a relação negativa entre a estrutura de capital e a adesão aos níveis de governança. Observou-se ainda que as firmas se comprometem com a comunicação entre elas e stakeholders enquanto o ambiente institucional demanda mais atenção. Seria possível ainda entender, através da média do endividamento, que as dívidas das firmas estão mais alocadas no capital de terceiros, principalmente no longo prazo. A amostra atendeu a mais da metade dos itens de governança considerados pela pesquisa, sendo este resultado considerado satisfatório.

Através dos testes de correlação foi possível confirmar a hipótese de que existe um relacionamento, com sentido negativo, entre níveis de governança corporativa instituídos pela BM\&FBovespa e a estrutura de capital nas maiores empresas de capital aberto do Brasil. A governança tem como objetivo, dentre outros, minimizar conflitos de interesses, possibilitando assim maiores chances de captar recursos externos a custos menos onerosos, seja por capital ou mercado de ações, refutando, parcialmente, a teoria pecking order. Embora a teoria sugira que a captação externa via emissão de ações seja evitada, os índices apresentados sugerem que essas 
firmas podem recorrer ao autofinanciamento ou mesmo ao aumento do número de ações. Para a literatura discutida, a governança corporativa contribuiria nesse sentido.

Não foi possível obter relação entre o Índice de Qualidade de Governança Corporativa e as variáveis de endividamento e dependência financeira, refutando assim a hipótese em que presumia a relação entre a qualidade da governança e a estrutura de capital. No entanto, mesmo não dispondo dessa relação, foram observadas correlações significativas, com sentido negativo, no que tange às dimensões de estrutura de propriedade e controle, ambiente institucional e do relacionamento com investidores. A pesquisa contribui com informações que auxiliam para o surgimento de novos debates acerca do tema, sendo esta mais uma fonte de pesquisa onde a governança pode ser tida como instrumento que venha a auxiliar na tomada de decisões. Com isso, as empresas podem ser ajudadas a identificar aspectos da governança corporativa pontuais e pertinentes para gestão das fontes de financiamento.

A pesquisa realizada tem limitações importantes, tanto em relação a sua amostra quanto em relação aos índices. Com isso sugere-se que os próximos estudos empreguem mais índices que venham a contribuir com o estudo e que façam adesão a uma amostra maior e de períodos mais longos, verificando-se a influência temporal na relação da governança e da estrutura de capital. Sugere-se adicionalmente estudos que comparem os sistemas de governança adotados em diferentes países.

\section{REFERÊNCIAS}

ASSAF NETO, A. Estrutura e análise de balanços: um enfoque econômico-financeiro. 9 ed. São Paulo: Atlas, 2010.

BARROS, C. M. E.; SILVA, P. Y. C.; VOESE, S. B. Relação entre o Custo da Dívida de Financiamentos e Governança Corporativa no Brasil. Contabilidade, Gestão e Governança, v. 18, n. 2, p. 7-26, 2015.

BEZERRA, N. M.; APOLINÁRIO, A. K. N. Governança Corporativa e Endividamento: um estudo empírico nas empresas listadas nos segmentos da BM\&FBOVESPA nos anos de 2008 a 2012. In: Congresso USP de Controladoria e Contabilidade, 14., 2014, São Paulo. Anais... São Paulo, USP, 2014.

BM\&FBOVESPA - Bolsa de Valores de São Paulo. Disponível em: <http://www.bmfbovespa.com.br/>. Acesso em: 04 mar. 2017.

CAMPOS, C. Confronto das Teorias Pecking Order e Trade-Off: Evidências com Base nas Companhias Brasileira Abertas. 2008. 114f. Tese (Programa de Pós-Graduação e Administração de Empresas) - Universidade Presbiteriana Mackenzie, São Paulo, SP, 2008.

CICOGNA, M. P. V.; TONETO JUNIOR, R.; VALLE, M. R. O impacto da adesão a padrões mais elevados de governança sobre o financiamento empresarial. Revista de Administração da USP, v. 42, n.1, p. 52-63, 2007.

COSTA FILHO, J. C. B..; JÚNIOR, D. B. C. V.; DOMINGOS, S. R. M.; PONTE, V. M. R. Endividamento e qualidade da governança corporativas nas companhias listadas na 
BM\&FBovespa. In: Congresso Anpcont, 10., 2016, Ribeirão Preto. Anais... São Paulo: Anpcont, 2009.

CUNHA, P. R., \& POLITELO, L. Determinantes do nível de governança corporativa das empresas brasileiras de capital aberto do setor de consumo cíclico da BM\&FBovespa.

Advances in Scientific and Applied Accounting, v. 6, n. 2, p. 211-235, 2013.

CVM - Comissão de Valores Mobiliários. Disponível em: <http://www.cvm.gov.br/> Acesso em: 06 mar. 2017.

DAVID, M.; NAKAMURA, W. T.; BASTOS, D. D. Estudo dos modelos trade-off e pecking order para as variáveis endividamento e payout em empresas brasileiras (2000-2006). Revista de Administração Mackenzie, v. 10, n. 6, p 132-153, 2009.

FONSECA, C. V. C.; SILVEIRA, R. L. F.; HIRATUKA, C. A relação entre a governança corporativa e a estrutura de capital das empresas brasileiras no período 2000-2013. Revista Enfoque: Reflexão Contábil, v. 35, n. 2, p. 35-52, 2016.

IBGC - Instituto Brasileiro de Governança Corporativa. Disponível em: <http://www.ibgc.org.br>. Acesso em: 7 mai. 2017.

IBGC. Código das Melhores Práticas de Governança Corporativa. 5 ed. São Paulo: IBGC, 2015.

IQUIAPAZA, R. A., AMARAL, H. F., ARAÚJO, M. D. S. B. D. Governança Corporativa e Divulgação de Relatórios Financeiros Anuais. Revista de Administração Mackenzie, v. 9, n. 3, p. 157-183, 2008.

J. P. MORGAN. DR Market Activity. Disponível em: <https://www.adr.com/Investors/Markets>. Acesso em: 03 mar. 2017.

LAKATOS, E. M; MARCONI, M. A. Metodologia do trabalho científico. 7 ed. São Paulo: Atlas, 2009.

LAMEIRA, V. J.; NESS JÚNIOR., W. L. Os determinantes da qualidade da governança praticada pelas companhias abertas brasileiras. Revista de Negócios, v.16 n 3, p 33-52, 2011.

LAUX, G. Mercado de crédito no brasil: características e respostas a choques. 2006. 90 f. Dissertação (Mestrado) - Escola de Economia de São Paulo da Fundação Getúlio Vargas, São Paulo, 2006

LAZZAROTTO, M. Governança corporativa: uma exploração de informações. Revista UNEMAT de Contabilidade, v. 4, n 7, p 90-102, 2015.

LIMA, S. H. O.; OLIVEIRA, F. D.; CABRAL, A. C. A.; SANTOS, S. M.; PESSOA, M. N. M. Governança corporativa e desempenho econômico: uma análise dos indicadores de desempenho entre os três níveis do mercado diferenciado da BM\&FBovespa. REGE Revista de Gestão, v. 22, n 2, p. 187-204, 2015.

MALHOTRA, N. K. Pesquisas de marketing: uma orientação aplicada. 4 ed. Porto Alegre: Bookman, 2006.

MARQUES, V. A.; ALVES, R. F. C.; AMARAL, H. F.; SOUZA, A. A. Relação entre níveis de Governança, política de dividendos, endividamento e valor das empresas brasileiras.

Revista de Evidenciação Contábil \& Finanças, v. 3, n.2, p. 4-26, 2015.

MEDEIROS, O. R., DAHER, C. E. Testando a teoria de hierarquização de fontes de financiamento nas empresas brasileiras. Revista Contabilidade \& Finanças, v.16, n.7, p.3745, 2005. 
MYERS, S. C. Capital Structure Puzzle. Journal of Finance, v. 39, n. 3, p. 575-592, 1984.

MOURA, F. F. D. M.; ALVES, M. D. S; LUNA, R. G. Endividamento: Uma discussão sobre o comportamento das empresas listadas no segmento de governança corporativa da BM\&FBovespa. In: Simpósio de Excelência em Gestão e Tecnologia - SEGeT, 10., 2013, Rio de Janeiro. Anais... Rio de Janeiro: AEDB, 2013.

PRAZERES, R. V.; SAMPAIO, Y. S. B.; LAGIOIA, U. C. T.; SANTOS, J. F.; MIRANDA, L. C. Fatores determinantes do endividamento: um estudo empírico no setor de telecomunicações brasileiro. Contabilidade, Gestão e Governança, v. 18, n. 2, p. 139-159, 2015 .

PROCIANOY, J.; SCHNORRENBERGER, A. A influência da estrutura de controle nas decisões de estrutura de capital das companhias brasileiras. Revista Brasileira de Economia, v. 58, n. 1, p. 122-146, 2004.

SANTOS, A. G. Comitê de auditoria: uma análise baseada na divulgação das informações de empresas brasileiras. 2009. 175f. Dissertação (Mestrado em Controladoria e Contabilidade: Contabilidade) - Faculdade de Economia, Administração e Contabilidade, Universidade de São Paulo, São Paulo, 2009.

SANTOS, J. G. C.; VASCONCELOS, A. C.; DE LUCA, M. M. M. Internacionalização de empesas e governança corporativa: Uma análise das maiores companhias abertas do Brasil. Advances in Scientific and Applied Accounting, v 8, n 3, p 300-319, 2015.

SAMPIERI, R. H.; COLLADO, C. F.; LUCIO, P. B. Metodologia de pesquisa. 3 ed. São Paulo: McGraw Hill, 2013.

SCARPIN, J. E.; MACOHON, E. R.; DALLABONA, L. F. Variabilidade dos índices de endividamento em relação à adição dos passivos contingentes na estrutura patrimonial das empresas listadas na BM\&FBOVESPA. Revista de Contabilidade e Organizações, v. 22, p. 3-14, 2014.

SILVA, A. G. D.; ROBLES JÚNIOR, A. Os impactos na Atividade de auditoria independente com a introdução da Lei Sarbanes-Oxley. Revista Contabilidade \& Finanças da USP, v. 19, n. 48, p. 112 - 127, 2008.

SILVA, A. L. C. Governança Corporativa e Decisões financeiras no Brasil. 2. ed., Rio de Janeiro: Mauad Editora Ltda., 2005.

SILVEIRA, A. D. M. D. Governança Corporativa, Desempenho e Valor da Empresa no Brasil. Dissertação (Mestrado) - Faculdade de Economia, Administração e Contabilidade da Universidade de São Paulo, São Paulo, 2002.

SILVEIRA, A. D. M..; PEROBELLI, F. F. C.; BARROS, L. A. B. C. Governança corporativa e os determinantes da estrutura de capital: evidências empíricas no Brasil. Revista de

Administração Contemporânea, v. 3, n. 12, p. 763-788, 2008. 